\title{
Silent uterine rupture in second trimester: a differential diagnosis to remember
}

\section{Rajlaxmi Mundhra*, Anupama Bahadur, Kiran Kunwar, Juhi Mishra, Ankita Yadav, Debashish Das}

Department of Obstetrics and Gynecology, All India Institute of Medical Sciences, Rishikesh, Uttarakhand, India

Received: 10 May 2020

Accepted: 10 June 2020

\section{*Correspondence:}

Dr. Rajlaxmi Mundhra,

E-mail: rmundhra54@yahoo.com

Copyright: ( $)$ the author(s), publisher and licensee Medip Academy. This is an open-access article distributed under the terms of the Creative Commons Attribution Non-Commercial License, which permits unrestricted non-commercial use, distribution, and reproduction in any medium, provided the original work is properly cited.

\begin{abstract}
Spontaneous silent uterine rupture is a life-threatening emergency situation requiring immediate laparotomy. High index of suspicion is key to prevent maternal mortality as at times the presentation can be nonspecific. Authors herein present a case of spontaneous silent uterine rupture during second trimester of pregnancy wherein the diagnosis was initially missed. To the best of authors knowledge, only a few cases with spontaneous fundal second trimester uterine rupture have been recorded so far.
\end{abstract}

Keywords: Hemoperitoneum, Fundal rupture, Uterine rupture

\section{INTRODUCTION}

Silent uterine rupture is rare but serious life-threatening pregnancy event that predisposes the mother to severe hemorrhage. Incidence is 1 in 16000 deliveries. ${ }^{1}$ Risk factors include previously scarred uterus, inappropriate prostaglandin or oxytocin usage, previous instrumental delivery, dilatation and curettage and vigorous fundal pressure. ${ }^{2,3}$ Authors herein describe a misdiagnosed case of spontaneous silent fundal uterine rupture at 28 weeks of gestation leading to fetal demise.

\section{CASE REPORT}

A 22-year-old G3P0A2 at 28 weeks of gestation was referred to the emergency area with breathlessness, abdominal distension and pain abdomen. Her previous two pregnancies were first trimester abortions with dilatation and curettage done in both. She had complaints of distension and pain abdomen for last seven days. She was admitted in a private nursing home wherein she underwent blood investigations. Ultrasound done five days prior to admission in the hospital (in private hospital) showed moderate ascites with hepatosplenomegaly with live fetus. She was found to be severely anemic and received two units packed red cell transfusion.

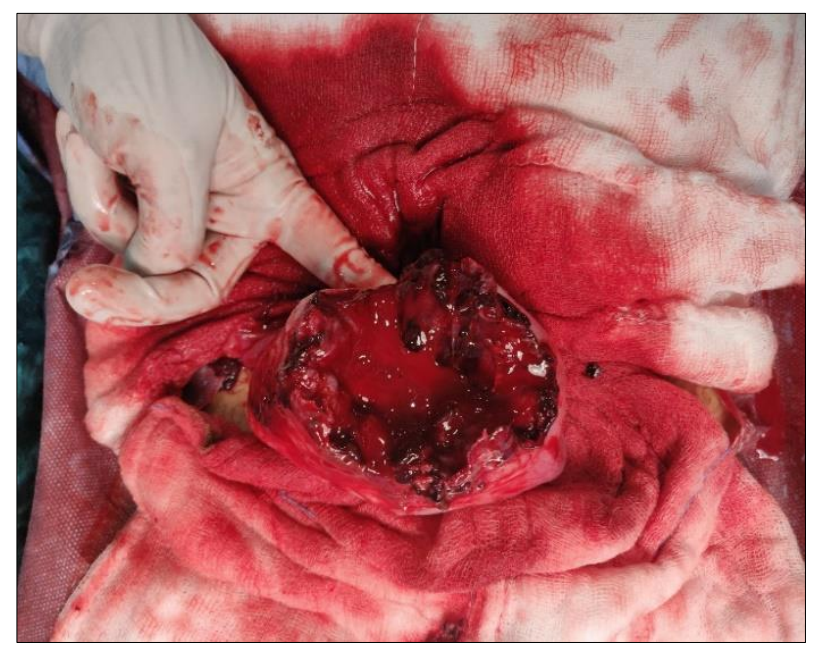

Figure 1: View from above (fundal rupture). 


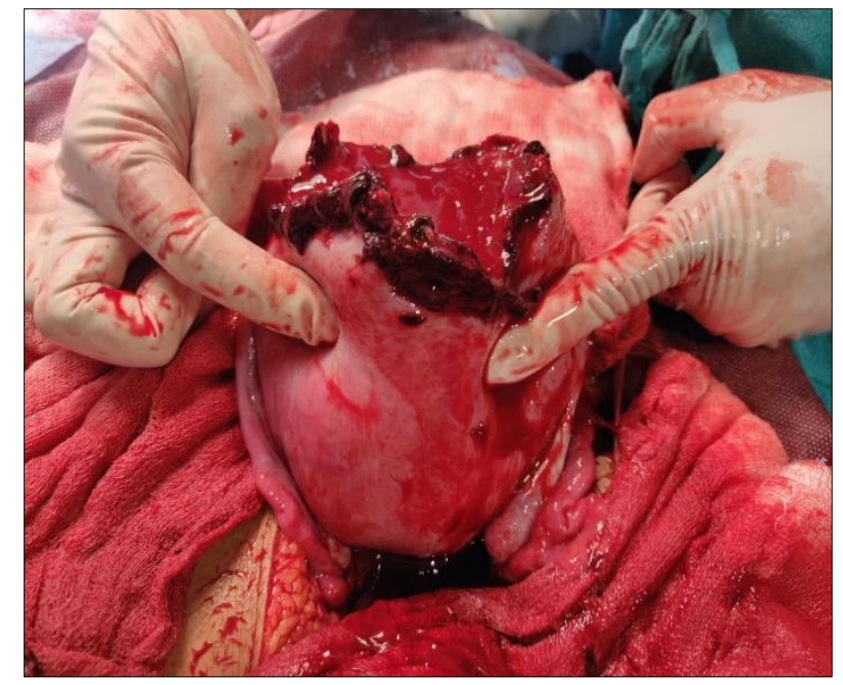

Figure 2: View from front (fundal rupture). Blue arrows point towards cornual structures.

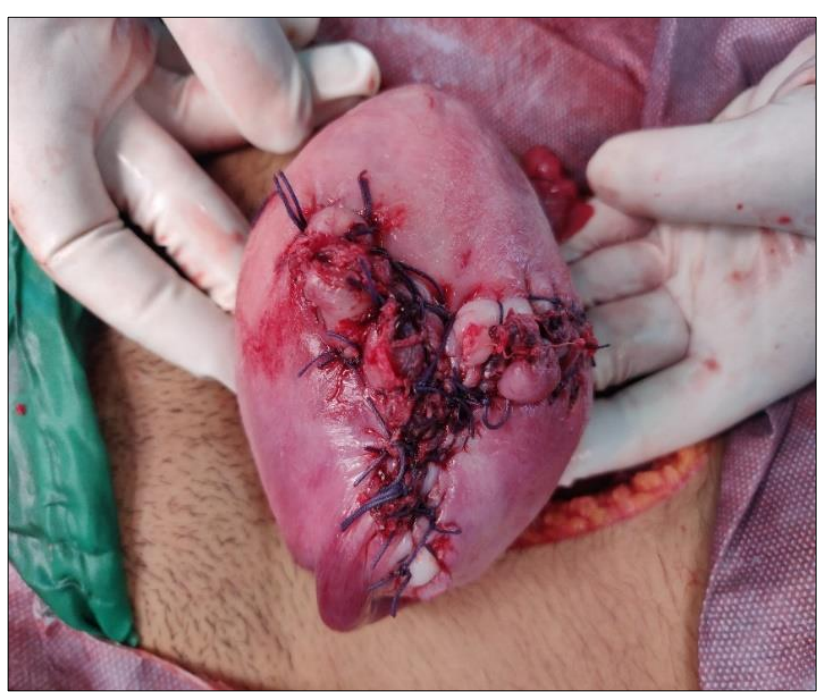

Figure 3: Uterus after repair.

On admission in study hospital, she was conscious but tachypnoea (respiratory rate of $34 / \mathrm{min}$ ) with sick look. She was severely anemic with pulse rate of $170 / \mathrm{min}$ and blood pressure of $90 / 60 \mathrm{mmHg}$. Abdomen was distended with no uterine contour. Fetal parts were easily felt and no fetal heart sound was heard. An urgent ultrasound by obstetrician showed a non-viable fetus with gross free fluid in abdomen and pelvis. Her hemoglobin report came as $4 \mathrm{gm} \%$. Emergency laparotomy was performed. Around 3 litres hemoperitoneum with a $5 \mathrm{~cm}$ rent at the uterine fundus was noted (Figure 1 and 2). Fetus and placenta were lying in abdominal cavity. After removing all blood clots with fetus and placenta, the fundal rupture was repaired in three layers (Figure 3). Intraoperatively, she received 4-units PRBC, 4 units FFP and 4 units platelet transfused. She was shifted to intensive care unit and further received two units PRBC. Postoperatively, she recovered well and was discharged on day 7 .

\section{DISCUSSION}

Uterine rupture is defined as disruption of all layers of uterus and can be categorized as partial or complete. Scarred uterus remains the most important risk factor. Risk of rupture with one previous scar is $22-74 / 10,000$ as compared to $0.5-2.0 / 10,000$ in unscarred uteri. ${ }^{4,5}$

Clinical presentation mimics acute abdominal pain with features of vaginal bleeding, fetal bradycardia and, more rarely, hypotension and hypovolemic shock. ${ }^{6}$ These features are more evident in a lower segment uterine rupture but in case of fundal defect, symptoms can be vague and misleading as was in this case. ${ }^{7}$ In the present case, patient had also hidden her history of previous two surgical abortions which further misguided the previous consultant. Fundal rupture results in accumulation of blood in peritoneal cavity and can present with abdominal distension and hemoperitoneum as was seen in this case.

Prompt surgical intervention with resuscitative measures remains the treatment of choice. Goal is to control the bleeding with repair of anatomical defect. Considering the hemodynamic status of the patient and taking into account her parity, age, size of uterine defect along with surgeons' expertise, decision need to be taken either to repair the defect or proceed with total/subtotal hysterectomy. But this can at times be quite challenging and requires massive transfusion facilities with intensive care unit back up.

\section{CONCLUSION}

Early diagnosis and prompt surgical intervention can significantly improve prognosis. Differential diagnosis of rupture uterus should be considered whenever a pregnant woman presents with abdominal pain, distension and severe anemia even if it is early gestation with no evident risk factors.

\section{Funding: No funding sources \\ Conflict of interest: None declared \\ Ethical approval: Not required}

\section{REFERENCES}

1. Miller DA, Paul RH. Rupture of the unscarred uterus. Am J Obstet Gynecol. 1996;174:345.

2. Wang PH, Yuan CC, Chao HT, Yang MJ, Ng HT. Posterior uterine wall rupture during labor. Hum Reprod. 2000;15:1198-9.

3. Pan HS, Huang LW, Hwang JL, Lee CY, Tsai YL, Cheng WC. Uterine rupture in an unscared uterus after application of fundal pressure. J Reprod Med. 2002;47:1044-6.

4. Green-top Guideline Number 45. London: RCOG Press. Royal College of Obstetricians and Gynaecologists: birth after previous caesarean birth. 2007. 
5. Ofir K, Sheiner E, Levy A, Katz M, Mazor M. Uterine rupture: risk factors and pregnancy outcome. Am J Obstet Gynecol. 2003;189(4):1042-6.

6. Walsh CA, Baxi LV. Rupture of the primigravid uterus: a review of the literature. Obstet Gynecol Surv. 2007;625:327-34.

7. Sun Y, Huang J, Kong HF. Spontaneous rupture of unscarred uterus in the third trimester after in vitro fertilization-embryo transfer because of bilateral salpingectomy: a case report. Medicine (Baltimore). 2019;98(48):e18182.

Cite this article as: Mundhra R, Bahadur A, Kunwar K, Mishra J, Yadav A, Das D. Silent uterine rupture in second trimester: a differential diagnosis to remember. Int J Reprod Contracept Obstet Gynecol 2020;9:3081-3. 